\title{
Right to safe water \& criminalization of its pollution as an environmental crime in Iran regulations \& international documents
}

\begin{abstract}
Context and objective: Water is one of the most important factors in creating creatures and is a source of life. On the attitude of the Iranian holy to water, every stream in the holy land the great civilizations formed. Take another view water is main focus on developing countries and access and benefit of this vital resource confronted with economic, social and environmental issues and impacts deeply on all these dimensions. With this in mind, the purpose of this paper is to study water pollution in Iran law and international documents.
\end{abstract}

Research method: The current research is using description-analytic method as well as digital-library sources.

Findings: Water pollution affects the status of other organisms, so water pollution as an environmental element should be avoided. Iran's regulations have criminalized water pollution and numerous international documents have required governments to criminalize this environmental crime.

Conclusion: Water pollution is a major global problem that requires continuous and rigorous assessment of water resources policy at all levels. Realistic and rigorous management plans based on the needs of future generations require the prevention and management of water pollution as an environmental crime.

Keywords: water pollution, environmental crime, Iran regulations, international documents
Volume 7 Issue 6 - 2019

\author{
Jamal Beigi \\ Assistant Professor of Criminal Law \& Criminology, Islamic Azad \\ University, Iran
}

\begin{abstract}
Correspondence: Jamal Beigi, Assistant Professor of Crimina Law \& Criminology, Maragheh Branch, Islamic Azad University, Maragheh, Iran, Email jamalbeig@iau-maragheh.ac.ir
\end{abstract}

Received: November II, 2019 | Published: December 31, 2019

\section{Introduction}

The third generation of human rights refers to the set of generations which directly or indirectly affects all human beings and future generations. Realization of these rights in a way that benefits everyone involved and violation of it will lead to damage to human society. Benefit from a healthy environment is a law that is reviewed in terms of the generation ${ }^{1}$ is one thing that pollution is harmful to the environment, "water pollution", ${ }^{1}$ urban sewage and wastewater discharge in the river considering the proximity of the river into people life, follow numerous environmental consequences. ${ }^{2}$ On the other hand, in all the world water is in critical condition. At the session of the UN agency for the environment, which was held in Kyoto, Japan, it is estimated that by 2015 number of people who do not have access to potable water reduced by half.

Water in environmental during precipitation processes in the surface and penetrate into the ground and circulate underground. In the meantime, although the impact of human activity on the river is undeniable, however, the history of human intervention in rivers has been not very successful. Each year, about 2.2 million people die due to water-related diseases. ${ }^{3}$ Because of pollution in water sources as sketched in Figure 1, experts from the United Nations, know one of

'The term "water pollution" in this article is: The increase in the amount of any reagent, whether chemical, physical or biological, that changes its properties and its essential role in its specific uses. the most important tasks of country in the 21 st century and at the beginning of the third millennium, the fight against pollution, rising rivers and the seas and oceans. ${ }^{4}$

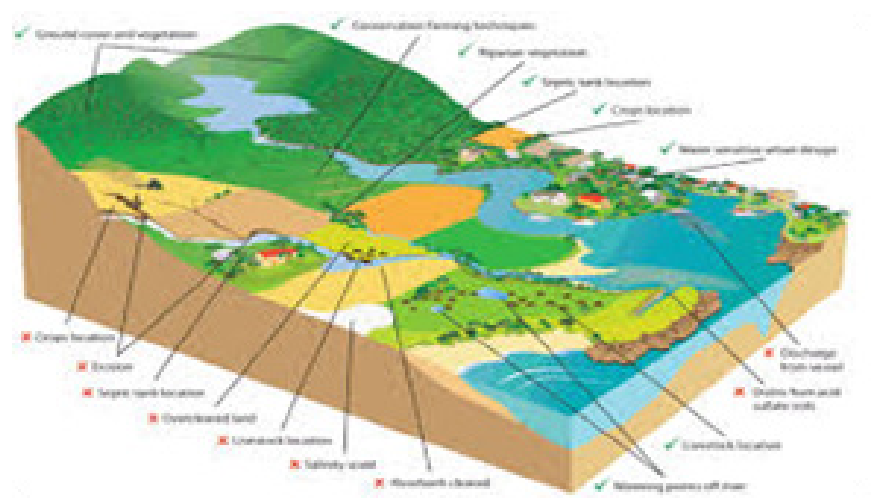

Figure I Classification of possible pollutions of water resources. ${ }^{4}$

What is true is that water resources are not being used properly and due to lack of water and rapid population growth, humans pollute water resources as a serious threat to his life(Table 1). ${ }^{5}$ The entry of industrial wastes, agricultural, chemical and toxic to water resources, water pollution in addition to the health and environmental risk to humans, animals and plants with biological hazards poses problems. ${ }^{6}$ 
Table I List of types of water resources pollution events

\begin{tabular}{lll}
\hline Row & Human-made events & Natural events \\
\hline I & Industrial Activities & Flood \\
2 & Agricultural \& Horticultural Activities & Earthquake \\
3 & Urban Areas & Volcano \\
4 & Waste Landfill & Landslide \\
5 & Areas of Use of Radioactive Materials & Fire \\
6 & Shipping Events & Drought \\
7 & Transmission Lines \& Oil Tanks & \\
8 & Explosions \& Fires & \\
9 & Mining Operations & \\
10 & Deliberate \& Subversive Activities & \\
\hline
\end{tabular}

Exclusive sovereignty over natural resources is the right of governments. State sovereignty and exclusive jurisdiction over its own territory, originally meaning they can only rights policies and right related to natural resources and environment to develop their land. The limited area of sovereignty over natural resources is:

1. The land within the borders of the underlying soil.

2. Domestic water such as lakes, rivers and streams.

3. Territorial sea and its bed and subsoil resources.

4. The space above the territory, internal waters and territorial sea as far as the legal system of the space above the atmosphere begins.

However, government has limited law and other areas including adjacent areas, close to the territorial sea, continental shelf, bed and subsoil and exclusive-economics area as well. Apart from the above, seas and its bed and subsoil, outer space and Antarctic regions is not governed by any country and why these areas are sometimes interpreted as universal joint. ${ }^{7}$ Information for citizens in terms of pollution rights reserved. Knowing is the people's right.

They have the right informed to crisis situations pollution and destructive industrial and manufacturing activities that threaten their health and life, citizens are entitled to the description of the projects affected by the government and government agencies are informed. The right to environmental information, especially information in Convention 1998 Denmark (ARHUS) and the twentieth statement of the United Nations Conference on the Human Environment (Astklhm Act of 1972) listed. The documents and statements on the free flow of scientific information and transfer of experience has been emphasizing on problem solving environment. ${ }^{3}$

\section{Legal resources on the right to safe water}

The natural environment refers to the living environment, which is the gift of God and played no role in the formation of human rights, including forests, meadows, mountains, plains, rivers, seas, lakes, marshes, landscapes, etc., elements of the natural environment, including biotic factors (plants and animals) and lifeless factors (soil, climate). ${ }^{8}$ Through the grace of God, water as one of the main elements of life in all living organisms play an important role and various water and therefore avoid all human societies has been around in some form. One of the most important sources of international environmental law invoked to deal with environmental risks and threats it in addition to these functions is to regulate the behavior of the function of international law.

Accordingly, environmental regulations have predicted the causes of environmental degradation and avoid it. When there are serious threats or irreversible damages, lack of full recognition of the threat should not be a reason to postpone the criteria to prevent environmental degradation. Irreparable damage include the extinction of animal and plant species, soil erosion or the discharge of durable pollutants into the sea which can cause irreversible condition and in a more optimistic if the damages are compensated for the cost of restoring it is very expensive. Scientific experts believe that the necessity of preventing the destruction of the environment ecologically and economically as a golden rule into account.

\section{International documents}

Almost all international environmental documents to prevent the destruction of the environment as a fact acknowledged that most of the pollution of the sea, domestic water, is conservation of air and living resource. ${ }^{9}$ Countries are committed to working in conservation and many international documents including the Stockholm Declaration of 1972, the Rio Declaration of 1992, some of the UN General Assembly resolutions and international judicial tribunals, the commitment to cooperation have been identified. Commitment to cooperation, a range of financing and technology cooperation, such as training courses, exchange of information and advice and helping the environment and so on is an emergency. The Court reviewed the case of Hungary and Slovakia, on the principle announced country Slovakia for failing to cooperate in good faith with its obligations under international law is not fulfilled. ${ }^{9}$

Ramsar convention as the founder of the International Convention on Iran, the world's oldest Inter-governmental treaty with emphasis on conservation and sustainable use of nature and the International Convention on the protection of wetlands that mission the convention for the protection and rational use of wetlands through local, national actions and international cooperation as a step in achieving sustainable development throughout the world. States Parties to the Ramsar convention are eligible to register at least one site in the list of wetlands of international importance. Ramsar wetlands on the site at the national level to achieve a new status and the international community for its outstanding value and states are considered wetlands and for all humanity.

On the other hand, the wetlands that for reasons such as drought, improper operation, and faced with the destruction endangered in wetlands list threaten by destroy the names are listed Montero and lose its place in the Ramsar List, in this case, immediate action by the other members of the Convention on Wetlands done to improve the situation..$^{10}$ Nevertheless, on 08.01.1972, the representative of the Convention signed in Paris by half of Iran under the single article of the law and the government approved the membership of the Convention (Adopted on 10.12.1973) has acceded to this Convention. ${ }^{11}$ Resolution No. XXIX 3281 dated 28 October 1982, World Charter for Nature in the field of environmental protection, with an Introduction and 24 of the United Nations General Assembly has passed. ${ }^{12}$ Under the Charter should be protected of nature and development in order to ensure conservation and the waste of natural resources and the fight against administrative regulations must be in line with this concept, fully applied to the conservation of nature, ${ }^{12}$ United Nations Environment Program me UNEP called for short, By virtue of Resolution No. 
XXVII 2997 United Nations General Assembly on December 15, 1972 was born.

It is headquartered in Nairobi (capital of Kenya) is the center of United Nations activities in the field of environment. Declaration of Stockholm in 1972 the first international instrument that is determined to be a human right focuses on a healthy environment. The second principle of the Declaration states that the earth's natural resources, including water, air, plants, and natural ecosystems must be through careful planning and management to protect and preserve for the benefit of present and future generations. Article 21 as well as Article 3 of the Convention on Biological Diversity 1992 and the first paragraph of Article I of Forests 1992, according to the UN Charter and international law, sovereign right of states to exploit their natural resources pursuant to their own environmental policies have been identified. ${ }^{3}$

Declaration April 26, 2002 New Delhi, affirming the duty of governments to address the needs and aspirations of future generations, protect and preserve and enhance the natural environment, especially water and air management systems, biodiversity, animals and plants of the common heritage of mankind's problems. ${ }^{13}$ World commission on environment and development, sustainable development is development which meets the needs of the present without reduce the ability of future generations to meet its needs. ${ }^{14}$ The reasonable use one of the main components of the environment, environmental assessments conducted as an international legal mechanism. ${ }^{15}$ Environmental assessment is to evaluate all the possible effects of development projects and delivery of strategies for reducing the impact on the environment. ${ }^{16}$ Benefit from a healthy environment from the perspective of regional documents is not contradictory. Article 24 of the African Charter on Human and People's Rights as the Additional Protocol of San Salvador (Additional Protocol to the American Convention on Human Rights), it clearly is poetry all nations have the right to benefit from a satisfactory environment and have the right to development. ${ }^{1}$

\section{Iran regulations}

According to Article 2 of the Penal Code, adopted in 2013, ${ }^{17}$ environmental crimes, any act or mission that resulted in severe damage to the environment and to human health and life is end a greed. ${ }^{8}$ Under scrutiny from various angles can deal with environmental crimes. A feature of environmental crimes endangering human health and life from this perspective it can be classified as crimes against persons or against the physical integrity. Severe damage to the environment, resulting in damage to public and private property is another characteristic of this type of crime. So from this point of view, it can be from the crimes against property or the property studied. Other characteristics of environmental crime are the consequences of it. For these offenses have adverse psychological effects on society and on the other hand, which she intended to cause harm to a particular person, all organisms, including humans negatively affected as well. So it can be placed in the category of crimes against public peace. ${ }^{18}$ Regardless of what you did with this crime is viewed, regardless of what you did with this crime is viewed, and it can be in two categories: crimes against the environment of the organism, offenses against the environment and in animate elements is divided. Water pollution is an environmental crime, including crimes committed in the category of inanimate environment to be investigated. According to paragraph (c) of Article 104 of Act of the Third Plan of Economic, Social and
Cultural Development of the Islamic Republic of Iran Approved $2000 ; ;^{19}$ in order to reduce pollution of the environment, particularly in the context of natural resources and water resources, production.

Units are required to comply its technical characteristics with the terms of the environment and act to reduce pollution. Costs in this case are as an acceptable cost to the unit. The units that would refrain from activities that cause pollution and environmental degradation, fines proportionate to the damage and getting back into the general revenue as well as the annual budget bills for the implementation of environmental costs. Regulations of this section include the amount of the charge and the cost to the EPA proposed by the Committee of Ministers.

\section{Criminalization of water pollution as an environmental crime}

Due to the serious environmental impacts and consequences of water pollution, this environmental crime has become criminalization in international law and governments have been bound by conventions required to adopt measures to prevent and combat water pollution. In the Iran legal system, influenced by Islamic teachings as well as international requirements, while paying serious attention to environmental protection in the constitution, water pollution has been criminalized under the ordinary regulations.

\section{International law}

Environmental degradation occurs even when out of the borders of a country, may cause global damage, including damage to the ozone layer, global warming, climate change, soil erosion, desertification and so on. ${ }^{7}$ Should not be forgotten that there are three major risks, threatens the planet: nuclear war, climate change and biodiversity loss. With the disappearance of the bipolar system and the threat of nuclear war has subsided somewhat climate change as drought fortunately, soon appeared and the temperature rise of the global mind is aware of the dangers. Although the risk of loss of biodiversity as natural heritage is not less than two of the above phenomenon, but the risks are lower, is taken into consideration.

Biodiversity is item that its destruction dimension is something that is beyond human imagination. Loss of biodiversity means the loss of habitats, species of flora and fauna and simplifies the diversity of life forms and to neglect the continuing loss of biodiversity, restriction of human progress in all fields and disarmed him against diseases and endangerment of life and survival of human beings to follow. ${ }^{20}$ The course is now in 80 countries arid and semi-arid with 40 percent of the world's population in regions of North Africa, parts of India, North China, Middle East, Mexico, the United States and West Asia periodic faced with drought. In the US Great Plains in Texas to Montana every year between 35 days and every ten years, are between 75 to 100 days of drought. Consequences of social, economic and environmental aspects of this phenomenon are hidden ones. ${ }^{21}$ Encounter with the phenomenon of drought, among the major issues in the 1992 World Conference "Environment and Development" was introduced in Brazil. $^{22}$

One of the documents of the meeting called Agenda 21 (AGENDA 21 ), referring to the effects of desertification threatens the Earth's land also called on governments to create or strengthen national systems for data collection and the social and economic effects of drought and desertification as well as strategies to consider. ${ }^{23}$ 


\section{Iran law}

In 1941 the first issue of water pollution in the prohibition in Article 11 of how to prevent sexually transmitted diseases and infectious diseases has been proposed. ${ }^{24}$ To Article 60 of the National Water Act and the Act of 27/4/1968, ${ }^{25}$ polluting rivers and streams deliberate public and streams and reservoirs and aqueducts sources and wells by adding foreign substances is prohibited and the offense. According to Article 2 Water Pollution Prevention Regulations Adopted $24.09 .1984,{ }^{26}$ apply to any action that would provide water pollution is prohibited. Paragraph 2 of Article 10 of the statute is "Water pollution is the change in solution or suspension, or a change in temperature and other physical properties and chemical and biological water to the extent that it is destined for consumption, harmful or useless it".

These losses can be noticed that the river is vital sources of danger to human or hinder its activities or change the quality of the application and its quality. ${ }^{17}$ Thus, the mass of water pollution caused by chemical substances and physical agents alter the degree to which it is normally achieved and thus the source of contamination can vary. Article 46 of the Act of equitable distribution of water, adopted on $16 / 12 / 1982^{27}$ also contaminate the water is prohibited. It is noteworthy that the pollution of seas and lakes and trans-border Rivers with oil, the parliament has passed a law on 14.11.1975 which pollute the river water the internal borders and territorial sea by oil or oily mixture is crime. The paragraph of Article 60 of the Islamic Republic of Iran in the Persian Gulf and Oman Sea Zones Act of 21.01.1993, ${ }^{28}$ create any pollution of the marine environment, contrary to the provisions of the Islamic Republic of Iran has declared a crime. It is important to note that in order to protect the Caspian Sea environment, the "Caspian Structural Environmental Protection Convention", which Iran has ratified in the 2005 , provides all contaminant resources and rational and sustainable use of Marine sources have indicated..$^{29}$

In this connection, it can also refer to the Regulations on Environmental Health Act 10.12.1992 that the contamination of public drinking water is prohibited. Finally, the criminal nature of the conduct of the Penal Code should be noted Article 688 of the Act, contaminated drinking water or contaminated drinking water distribution or pour toxic materials into rivers is prohibited and the perpetrators punished if certain rules are more severe will be sentenced to imprisonment up to one year and if the water is contaminated, leading to death or disability or injury to a human being in addition to the punishment of the perpetrator shall be punished and pay compensation for damages shall be sentenced to pay in any case. ${ }^{11}$

Several studies in recent years have indicated that most claims the DOE offices and industrial units that somehow the cycle of pollutants into the environment has been made under this clause. ${ }^{30}$ The most important cases of water pollution as an environmental crime are:

a) Deliberate contamination of rivers and streams and public canals, reservoirs, sources, aqueducts, wells by adding foreign substances.

b) Pollute the marine environment.

c) Pollute the public drinking water.

d) Infect domestic and offshore waters of the border river of Iran by oil or any oil mixture. ${ }^{31}$

\section{Conclusion}

What is true is that due to the rapid increase in population and water crisis, water resources are not being used properly. Realistic and detailed management plans are based on the needs of future generations, the need to prevent water pollution and to reduce the amount of water to prevent them. And transport of pollutants in the water industry in the long term to the rest of the way to deal with water pollution. Alternatively, citizens in the form of NGOs in order to apply various principles such as Article VIII of the constitution with the participation of the environmental education and informing citizens and government rapidly along the right of environmental law, by joining international treaties and laws on the criminalization of environmental damage any intentional or unintentional, directly or indirectly to human health, animal or plant by creating an imbalance in the natural environment, to tackle environmental pay crimes such as water pollution. Finally, in order to eliminate serious water pollution damage, it is suggested that, in addition to the involvement of the community council in adopting preventive situational and social strategies, the legislator should also criminalize all aspects of water pollution as an environmental crime.

\section{Acknowledgments}

None.

\section{Conflicts of interest}

The author declares there are no conflicts of interest.

\section{References}

1. Nasr Isfahani A. Benefit from a Healthy Environment; the Basic Right of all Generations, Bar Association Newsletter, No. 44, 2009.

2. Firouzi M. Right on the Environment, Printing Tehran, SID, 2005.

3. Beigi J, Khoshyari Hajji Baba R. Overview of the Environmental Crimes of zayanderood; Relying on International Documents, Conference of the Water, zayanderood \& Law, Association of Isfahan, 2012.

4. Serhadi B. Identification \& Classification of Types of Pollution in Water Resources, Section I, 2019.

5. Saduq MB. Population, Environment, Future, Environmental Quarterly, No. 3, 2001.

6. Itezad SM, Malek Chashm Siahef Z. Water \& Diseases, Environmental Quarterly. 1996;3(3).

7. Dabiri F, Poorhashemi SA, Rousta FA. Review of the Principles \& Concepts of International Environmental Law with a View to Sustainable Development, Environment, Science \& Technology. 2009;11(3).

8. Ghavam M. Criminal Protection of the Environment, Tehran, Environmental Protection Agency. 1996.

9. Piri M, Qasemy N. Legal-Judicial Review of the Role of Civil Rights Actions in the Environment, Environmental Science \& Technology. 2009;11(3)

10. Salimi Torkamani H. A Review of the Environmental Problem from the Perspective of International Law, Environmental Lake, Quarterly Strategy Twentieth Year. 2011.

11. Taghizadeh Ansari M. Criminal Law Environmental, Printing Tehran, Ghomes. 1997.

12. Chassis Alexander. Introduction to International Environmental Rights, Vol. 1, Translated by Mohammad Hassan Habibi, Printing Tehran, Tehran University, 2000.

13. Dehli Declaration on Principles of International Law Relating to Sustainable Development, April 2002.

14. Kardavani Parviz. Drought \& Ways to Deal with Iran. 2nd edn. 2007. 
15. Farrier David, Linda Tucker. Wise Use of Wetlands under the Ramsar Convention: A Challenge for Meaningful implementation of international law. Journal of Environmental Law. 2000;12(1):21-42.

16. Craik Neil. The International Law of Environmental Impact Assessment: Process, Substance \& Integration. Cambridge University Press. 2008.

17. The Penal Code Act. 2013.

18. Mohseni M. The General Criminal Law. 2003.

19. Act of the Third Plan of Economic, Social \& Cultural Development of the Islamic Republic of Iran Approved 2000.

20. Ameri, Mohammed Ibrahim. Accelerating the Destruction of Natura Heritage, Accessible Last CHN, 2003.

21. Miller GT. Environmental Sciences: Sustaining the Earth, Wadsworth Publications. California, Belmont, 1991.

22. Sharifi L, Beigi J. Dealing with Water Pollution in Iran Law Based on Transnational Documents. Journal of Nations Law. 2016;6(24).

23. UN. Press: Summary of AGENDA 21; Department of Public Information, New York Publications, the Secretariat of the Supreme Council of Information. 1997.
24. How to Prevent Sexually Transmitted Diseases and Epidemical \& Contagious Diseases Act. 1941.

25. The National Water Act and the Act of 04.27.1968

26. Water Pollution Prevention Regulations. Adopted on 24 / 9/1984.

27. Act of 16.12.1982 approved the distribution of water.

28. The Islamic Republic of Iran in the Persian Gulf Maritime Zones Act. Adopted on 21.01.1993 Oman.

29. Abdollahi M, Ramazani Qavam Abadi MH, Faryadi M, et al Environmental Criminal Law: Considerations and Solutions. Official Journal of the Islamic Republic of Iran. 2009.

30. Sangeeta Agarwal. Crimes against the Environment. 2015.

31. Vafadar Ali. Commitment and Responsibilities of Governments to Respect the Environment, Environmental Science and Technology. 2007;9(1) 